\title{
Academic Literacy: A Critical Cognitive Catalyst towards the Creation of Sustainable Learning Ecologies in Higher Education
}

\author{
Maseeeng Papashane* \\ Dipane Hlalele** \\ *School of Social Sciences and Language Education; \\ ${ }^{* *}$ School of Education Studies \\ University of the Free State, Qwaqwa campus, South Africa \\ E-mail:papashanem@qwa.ufs.ac.za; hlaleledj@qwa.ufs.ac.za
}

Doi:10.5901/mjss.2014.v5n10p661

\begin{abstract}
It is becoming customary in introducing discussions of academic writing in higher education to note that students, on entering a new field and environment, cannot be assumed to already know all they need to know about the academic language and learning their success will depend on. In addition, when students come to universities they bring with them literacy practices that may or may not be considered appropriate. The overlap, or lack thereof, between these literacy practices and those expected by the universities and distinct programmes to which they are seeking membership, is critical to students' chances of success. This article provides theoretical reflections on academic literacy discourses and concludes with arguments positioning academic literacy as a critical cognitive catalyst towards the creation of sustainable higher learning ecologies in higher education.
\end{abstract}

Keywords: Critical Cognitive Catalyst. Reading. Listening. Understanding. Academic Literacy. Sustainability.

\section{Introduction}

The concern that a noticeable number of students at institutions of higher learning posses unsatisfactory academic literacy levels has not lead only to debates and apportionment of culpability. Institutions of higher learning actively assess students' level of academic literacy with a view to, firstly, acquainting themselves with the seriousness of the problem and secondly, designing and implementing programmes to ameliorate the situation. It is our view (authors of this article) that lower than expected academic literacy limit epistemological access/academic participation and that there is an inalienable need to enhance students' academic literacy as a critical cognitive catalyst towards the creation of sustainable rural learning ecologies. A learning ecology framework foregrounds the fact that students/learners are simultaneously engaged in many settings and that they are active in creating activity contexts for themselves within and across settings. Whilst interactions within co-located settings are critically important for development, it is also clear that the learning processes that involve the creation of activity contexts in a new setting or the pursuit of learning resources that are found outside the primary learning setting are of paramount value (Barron 2006). The framework therefore, endorses the existence of a complex, dynamic but defined interplay between and within various settings (components of a learning ecology).

\section{Theoretical Reflections on Academic Literacy}

\subsection{Traditional views of literacy}

The meaning of the term 'academic literacy' is complex and, to an extent, subjective. A review of various texts on academic literacy suggests that the term is derived from the word 'literacy' which, according to Gee (2003:28), involves more than reading and writing. These are the components of literacy many take for granted and assume to be its sole characteristics. However, literacy is more than reading and writing, as each genre of written text has "its own rules and requirements ... and each has a culturally and historically separate way of reading and writing". In a related explanation of literacy, Pugh, Pawan and Antonmarchi (2000:25) state that literacy "involves the ability to understand and make use of information provided in a variety of forms entailing a variety of sign systems". In this explanation of literacy one finds more depth, as there is reference to the ability to decode information and understand it; two things that are not necessarily 
guaranteed even if one can read a passage. Thus literacy involves being able to move beyond merely receiving information through reading a text, but being able to put it to some kind of use - which they do not elucidate further.

As if to make up for the lack of depth of the explanation given by Pugh et al. (2000:25) Baynham (1995:2), whose perspective draws from linguistics, anthropology, and educational and social theory, defines literacy as "the uses of reading and writing to achieve social purposes in the contexts of use". This explanation reiterates that being literate involves much more than being able to read and write; it essentially involves reading with a purpose that goes beyond merely knowing information; and writing with a purpose as opposed to the mere ability to write. Furthermore literacy "...serve[s] social purposes in creating and exchanging meaning; ... is best understood in its contexts of use; and is ideological. Like all uses of language it is not neutral, but shapes and is shaped by deeply held ideological positions, which can either be implicit or explicit; and it needs to be understood in terms of social power" (Baynham 1995:1). The appropriateness of literacy in practice is informed by entrenched values which are generally taken for granted by readers and writers and in many cases not even apparent. The implication of such an understanding of literacy for academic literacy is that it is a specialised form of literacy that takes place in an academic social context where certain implicit and explicit ideologies are held with regards to the purposes of the social practices of amongst other things, reading and writing (Boughey 2000).

Furthermore, literacy carries social power (Baynham 1995; Turner 2004). Anyone who possesses the competence to carry out the social practices inherent in a particular kind of literacy is in a position to not only access information, but to synthesise it in ways deemed appropriate in order to communicate effectively in a given social context. Obviously the primary social context for academic literacy is the institution of higher learning, be it a university or a college, and the secondary social context where the academic literacy practice is on display is the workplace for which they have been trained.

Given the foregoing discussion on literacy, one should therefore not be tempted to define academic literacy superficially as "reading and writing skills in an academic context", thus providing a narrow and certainly inadequate definition of academic literacy similar to that which refers to academic literacy merely as "the ability to read and write the various texts assigned in university" (Braine 2002: 60-65). The adjective 'academic' in the two-word term 'academic literacy' is one that invokes the context in which literacy is practiced as well as the nature of the literacy practices inherent in literacy in the academe. Turner (2004: 24-26) consolidates these sentiments in identifying academic literacy as a cultural practice situated in an institution based on norms and values that place a premium on scientific rationality, clarity and precision in communicating ideas and findings to and by an ideal observer whose point of view is colonising and informed by the "epistemic norms of Eurocentric academic discourse". This take on academic literacy is clearly political in nature and has emancipatory undertones similar to those in Paulo Freire's (1970) Pedagogy of the oppressed. Turner's (2004: 25) stance seems to seek to expose academic literacy as a culture specific form of literacy; in particular a Western culture-specific norm. The Western cultural roots of academic literacy are expressed in the "virtues ... [of] economy and elegance as well as exactitude and certainty [in academic writing; virtues which ideally find expression in] logical exposition, concision in choice of lexis, and economy of style [in order to make for acceptable] academic writing... and a smooth read". Turner (2004) has introduced a covert dimension to academic literacy; that of "culture" and Eurocentrism as the basis of academic literacy. This perspective may have implications for investigating academic literacy levels amongst African students, many of whom, although educated in a western education system, are still strongly rooted in their own culture with its specific values and ideologies.

But that as it may, a sound exposition of academic literacy generally needs to take into consideration the style and the clarity of writing employed in encoding texts in the academe. In addition, the readability of academic texts is also a fundamental issue for consideration in explaining academic literacy. Furthermore, a broad definition of academic literacy needs to include skills such as, among other things, the ability to write with a specific audience in mind, research skills and the appropriate use of [course specific and general English] vocabulary (Braine 2002). The implication here, for a definition of academic literacy, is that the practice of academic literacy involves using the appropriate strategies to read and produce (write, speak) texts that are considered lingually and technically appropriate within various academic contexts.

The idea of culture as one possible part of academic literacy (Turner 2004) was introduced earlier in this section. The notion of the embeddedness of culture in academic literacy is reiterated by Reid (2005a:1) who explains academic literacy as a three-pronged skill involving Operational literacy, Cultural literacy and Critical literacy. Operational literacy for him refers to "competency in the language, especially written language". Cultural literacy refers to "learning a discourse or a culture, that is, how to communicate in the language of a specific group of people or a subject", while critical literacy "is understanding how knowledge is made and how it can be transformed".

In our experience and opinion as academics at a higher education institution, Reid's (2005a:1) provides the most 
comprehensive, in-depth and realistic definition of academic literacy at university, irrespective of the field of study in which a student is involved. Throughout their studies, students at university are expected to conduct independent research for various purposes either in the field or of literature. Invariably, they are generally required to answer questions posed in their given courses. In order to do this they not only have to read material efficiently, but they have to read with an open and critical mind so that they can judge information against prior personal and general knowledge, as well as subject specific knowledge. Furthermore, analysis and comparison of information may also be involved in the general process of evaluating information gained from research in the field and/or through reading literature.

The ultimate aim of academic literacy exercises carried out by students is often to have them synthesise new information that reflects a critical and objective thinking process. Thus academic literacy skills include amongst others "writing in clear sentences, spelling correctly and using punctuation correctly (Operational literacy); incorporating ideas from others into your work, structuring an essay, writing introduction and conclusions in an appropriate style, acknowledging ideas of others, that is, referencing (Cultural literacy); and analysing an assignment question, reading academic texts and reflecting critically on ideas and experiences (Critical literacy)" (Reid 2005b:1). It seems that in this perspective on academic literacy academic essay writing skills are central to academic literacy at university.

Although the above explanation of the skills involved in academic literacy suggests that the academic essay is fundamental to academic writing, it is not the only type of text according to which students' academic competence is judged at university. In other words the academic essay is not the only type of text through which students' academic literacy can be demonstrated. Students at university may also be involved, for example, in the writing of reports on experiments in the physical sciences and the life sciences. They may also design posters and advertisements as part of their continuous assessment, if they are studying marketing or English for example. In addition students may also be required to create spoken texts in the form of individual oral presentations (speeches) in various fields, group dramatic performances in the dramatic arts, mock trials in the study of law, and debates on topical issues in a variety of learning areas.

The fact that Reid's (2005a:1) definition of academic literacy has been expanded upon in terms of inherent skills that focus on the writing of academic essays only is not surprising, as the three core components of this definition of academic literacy were elaborated upon on a website for Faculty of Education students, whose writing tasks focus mainly on the writing of essays. Therefore the point that academic literacy is defined according to the general perspective held in a discipline is made indirectly. According to Reid (2005a:1) "each [discipline] is like a different culture. The culture of the Bachelor of Education differs from that of the Bachelor of Economics [or the Bachelor of Science]"; accordingly, the norms, and the expectations of lecturers and in each discipline will differ with regard to academic literacy. Hence my argument that a definition of academic literacy must accommodate the wide range of spoken and written texts expected of students of various disciplines at university. In addition to the afore-mentioned skills of cultural literacy, operational literacy and critical literacy, a broad definition of academic literacy might include aspects such as "technical literacy ... economic literacy, scientific literacy and academic vocabulary" (Reid 2005a:1).

Several studies have been done on academic vocabulary, knowledge of which is key to interpreting questions accurately, and therefore facilitating a process that in general involves finding the information related to those questions, and within that sea of information, being able to choose information which is most relevant to the question, so as to answer it correctly. This process may be followed for assignments and tests during the term, or for the purpose of studying for examinations at the end of a semester. In a study on different methods of vocabulary testing, Cooper and van Dyk (2003: 68) identify vocabulary size as a key component of language competence (and therefore a fundamental aspect of academic literacy); and argue that it influences ... quality of writing, level of reading comprehension and academic performance ... ". If students are to successfully complete academic tasks involving reading and writing academic texts, they must be able to make clear sense of what they read and also what is required of them, in terms of assignment instructions and guidelines.

Coxhead (2000:213) draws a distinction between the technical vocabulary and the academic vocabulary that students have to know as one of the points of departure for successful academic performance at all levels of study at university; knowing relevant technical and academic vocabulary is also a fundamental aspect of academic literacy. Technical vocabulary is the field specific vocabulary. Therefore students encounter vocabulary in this category very frequently as they engage in the academic challenges of their specific courses. Academic vocabulary, on the other hand, occurs with a relatively higher frequency than technical vocabulary, which can otherwise be thought of or referred to as the 'jargon' associated with a field of study or a discipline within that field. Therefore while technical vocabulary is associated with a field of study, academic vocabulary is not field- or discipline specific. It occurs across fields and disciplines and forms the foundation of communicating effectively and appropriately in an academic context.

In summarising this section on defining academic literacy, we may also take note of Warren's (2003:1) definition of 
academic literacy, which reflects a comprehensive and broad perspective on academic literacy. According to Warren (2003:1), academic literacy may be defined as "the complex of linguistic, conceptual and skills resources for analysing, constructing and communicating knowledge in the subject area". Thus academic literacy is an umbrella term for a set of inter-related competencies. It has sub-domains which both Ratangee (2007: 24-25) and Van Dyk and Weideman (2004a: 16) have described succinctly.

Both Ratangee (2007:24-25) and Van Dyk and Weideman (2004a) provide an explanation of academic literacy in clear and potentially measurable terms. They do so by indicating linguistic and cognitive behaviours and competencies characteristic of academically literate students. This is potentially capable of facilitating the curriculation of academic literacy interventions in multicultural and multilingual university contexts where such intervention is often needed. Furthermore Ratangee's (2007: 24-25) and Van Dyk and Weideman's (2004b) lists have the potential to facilitate valid assessment of academic literacy levels amongst students at university. In addition they bring together many components of the definitions of academic literacy discussed previously in this section. This is achieved through a focus on academic literacy as an overarching and cumulative practice involving interaction between language skills (knowledge of vocabulary, sentence construction, construction of different types of text); thinking skills (ability to argue, interpret, extrapolate, classify, compare, contrast); numeracy skills; and basic computational skills.

Ratangee (2007:24) mentions "identifying author's bias" with reference to critical thinking as a sub-skill of academic literacy. It is an aspect of critical thinking which, up to this point, has been absent from our discussion about academic literacy and the performances associated with it. Further review of the literature on academic literacy indicates that 'author's bias' in (academic) text or non-academic texts used for academic purposes (e.g. using an advertisement in a linguistics critical discourse analysis course) is a concept which is best revealed to and explored with students, particularly those in academic literacy development programmes, in relation to the notions of ideology in text, and discourse. The reason why 'author's bias' is best explored in relation to notions of ideology in text and discourse is that academic literacy is more than just a cumulative result of language, thinking, numeracy, computational and technical skills (e.g. referencing). In addition to these skills, students need to have "epistemic cognition, that is, understanding how subject knowledge is created and challenged" (Ratangee, 2007: 23); in order to be truly academically literate. Thus, to be academically literate, students in specific disciplines need measurable skills such as those described by Ratangee (2004: 24-25) and Van Dyk and Weideman (2004a). They also need to develop an understanding of knowledge creation in general in an academic context, and also from the vantage point of their field in a particular; which may be different from that of another discipline which has its own discourse within general academic discourse.

\subsection{New Literacy Studies}

The previously discussed traditional views seem to take a view of literacy and academic literacy that can be said to be a deficit view. It places students as dependent recipients of academic literacy who are otherwise without ant form of literacy or in other words illiterate and therefore dependent on custodians of such literacy to become literate. The current preferred approach to literacy conceptualisation and development is informed by a view that is generally more positive or asset-based as far as the participants in literacy studies are concerned. It posits students with different cultural backgrounds entering the mainstream higher education context as already literate, just in ways that are relevant to and reinforced by their cultural background which, for many additional language students at university is different from the dominant Western ideologies about literacy in higher education (Street, 2005: 417-418)

In the new literacy studies framework highlights the fact that ideas about literacy are always ideological and biased and never neutral or autonomous; what constitutes any form of literacy is indeed informed by cultural assumptions and ideologies (Street, 2005: 417-418). Indeed Lea (2004: 740) reminds us that "literacy is not a unitary concept; reading and writing - literacies - are cultural and social practices, and vary depending upon the particular context in which they occur". New Literacy Studies "treat language and literacy as social practices rather than technical skills to be learned in formal education" (Street, 1997: 47). Thus it can be expected that literacy will be influenced by the social background in which one becomes literate, in whichever way that may be. The notions of literacy events and literacy practices further help to emphasise the idea of literacy as being contextually situated and ideological. The former concept refers to "any event in which a piece of writing is integral to the nature of the participants' interactions and their interpretative processes" (Heath 1982 in Street, 1995: 2). They are "the particular events in which literacy has a role: they may be regular repeated activities" (Street, 1995: 2). The latter concept refers to "general cultural ways of utilising literacy that people draw upon in a literacy event" (Street, 1995: 2).

The implication of these two concepts for studying and developing academic literacy amongst a culturally and linguistically diverse cohort of students at South African university is that academics should develop sensitivity to 
disparate literacies which are a product of these different cultures and disparate relationships and experiences with reading and writing practices. The literacy practices acquired by these students at home should not be regarded as inferior (Street, 1997: 50). In other words students at South African universities should not be regarded as illiterate if they cannot display academic literacy practices. Rather they should be regarded as differently literate and in a position to become literate in the social practices that constitute academic literacy.

\section{Academic Discourses and Genres}

According to Boughey (2000: 281), "literacy involves knowing how to speak and act in a discourse". If one follows this line of thinking and takes a narrow view of academic literacy, it involves being able to speak and act in academic discourses. Thus the dimension of academic discourse is introduced into our discussion. Reid (2005b) attempts to explain academic discourse by pointing out that each school subject, for example, has its own style of literacy which includes a specialised vocabulary, and a specialised way of reading, talking and writing about texts. Therefore there are certain conventions that guide and indeed prescribe the production of text within a particular discourse.

Paxton (1998:137) uses Kress's (1985) definition of discourse in an attempt to illustrate how discourses operate and thus shape the production of text:

Discourses are systematically organised sets of statements which give expression to the meanings and values of an institution. Beyond that they define, describe and delimit what is possible to say... with respect to the area of concern of the institution, whether marginally or centrally. Discourse provides a set of possible statements about a given area and organises and gives structure to the manner in which a particular topic, object, process is to be talked about.

Thus academic discourse is to be understood as particular ways of constructing and interpreting text in different areas of the academe. These ways of constructing and of interpreting text and the content therein, are shaped by beliefs, values and perspectives of the academe as an institution, and as an institution comprising many parts, each with its own values, beliefs and perspectives which shape expectations and practices regarding students' academic literacy.

From a linguistics perspective, we note that the term 'discourse' is mainly, although not exclusively, associated with stretches of spoken language. The term also refers to instances of language use beyond the sentence level, as one finds in letters, newspaper articles and conversations. One of the figures at the forefront of theory on discourse is Foucault, who, in the seminal publication Language and Power (1989), focuses on exposing the subtlety and inevitability of ideology in written texts. In this context discourse refers also to written texts such as newspapers and advertisements in which certain values and worldviews may be embedded. Therefore discourses express ideological positions and inadvertently point to the dominance and naturalisation of certain genres of written language within the higher education system.

The academic essay is the dominant genre of written language in the academe (Carstens 2009:89). It may not be used with as much frequency in all disciplines in the undergraduate years, but once students move to the postgraduate level of study, they are expected to demonstrate depth of subject knowledge, academic literacy in the writing of extended essays and, should they wish to study further, a master's dissertation, and later a doctoral thesis. Next the discussion focuses on the socio-politics of academic literacy with the aim of situating academic literacy beyond the university and within the broader social context, i.e, within a learning ecology.

\section{Academic Literacy within a Learning Ecology Perspective}

A learning ecology framework foregrounds the fact that students/learners are simultaneously engaged in many settings and that they are active in creating activity contexts for themselves within and across settings. Whilst interactions within co-located settings are critically important for development, it is also clear that the learning processes that involve the creation of activity contexts in a new setting or the pursuit of learning resources that are found outside the primary learning setting are of paramount value (Barron 2004; Barron 2006). The framework therefore, endorses the existence of a complex, dynamic but defined interplay between and within various settings (components of a learning ecology). We therefore contend that academic literacy serves as a cognitive catalyst that that pervade cognitive activities in more than one settings.

\subsection{Speaking and listening skills}

In an ideal teaching and learning situation students are active participants who, in addition to taking down notes during lectures and private consultation with their lecturers, engage mentally and verbally in academic debate and in response to 
academic discourse. Therefore speaking, or speech, plays a fundamental role in the sharing of academic information between lecturers and students. In the teaching/learning situation, i.e. lectures and practical teaching, the lecturer's role is to use speech in addition to notes in order to facilitate students' acquisition of information and skills. The success of the teaching and learning efforts depends in part on students' selective listening for key information while taking down notes in an efficient, linear or non-linear manner, from the lecturer's written notes and also from what he/she and other students say during the class. It is apparent therefore, that "at university speaking, listening and writing often go together" (Weideman 2007: xii).

The tasks included in the course demonstrate the integrated manner in which language skills are used in academically literate behaviour. They focus on active participation in class discussions, small groups and individually. Students speak about personal details and opinions with regard to the traditions of their institution, and express their general preferences in writing and speech. They also hone their listening and speaking in tasks that require gathering personal information about their fellow students, listening to a dictation of a map of their campus, engaging in dialogue where they give directions to a stranger on their campus. Furthermore students do jazz chants, write down a list of words (nouns selected from Coxhead's Academic Word List) that are dictated silently by their lecturer, and find and write down adjectives associated with those words. They also practice note-taking in linear and non-linear formats. These tasks are likely to aid students in not just speaking and listening, but in capturing information during lectures, gathering information and studying, which are discussed next.

A set of tasks geared at impeccable information gathering is indispensible to cognitive endeavours on academic literacy development as efficient study and information gathering are part of the backbone of academic success and meaningful learning at university. Indeed successful study and adequate academic achievement at university are linked to ... the application of effective learning strategies (Barnes 1996: xi-ix; McWhorter 1992: iii) or "studying in the right way" employing an active approach (McWhorter 1992:13). Ultimately, this section of the course aims at encouraging a deep approach to learning in the university context. While the learning strategies part of the section compels students to reflect on their learning practices and experiences and also evaluate and their language learning ability. This part of the section also requires students to use the information gained in their reflection in developing and improving their own learning, and advising others on how to maximise their learning. Thus it lends itself to the achievement of genuine academic success founded on meaningful learning.

Meaningfulness in learning is enhanced by the information gathering tasks which also encourage students to engage actively with the content in the process of learning as they survey study-related information from a purposive sample, attempt to make sense of that information, explain their findings in writing several drafts of their report, create their own ideas about academic writing, and synthesise their ideas with those of other students. In completing these tasks students are compelled to engage in higher-order cognitive activities that require them to go beyond the level of knowledge and comprehension and "relate, argue, explain, apply, hypothesise and reflect" (Biggs, Tang 2009:27) on information. Thus students are familiarised with tasks that not only lend themselves to successful learning and study at university, but also foster understanding of the process through which academic research is carried out.

Arguably, successful study and information gathering at university hinges upon active involvement in these processes and "knowing how to use [information] to... interpret, evaluate and apply it to solve problems, create new ideas, or approach ideas in unique ways" (McWhorter 1992:17). Students' ongoing efforts at building knowledge and understanding of general and academic vocabulary will determine the extent to which they are able to create new ideas or express themselves adequately.

\section{Building Academic Vocabulary}

A lexicon comprising as many words as possible from the Academic Word List should aid competence in listening, speaking, reading, writing assignments and exams, researching and studying at university. The 'Academic word List' [AWL] is a very important specialised vocabulary for learners intending to pursue academic studies ... at the ... postsecondary levels., compiled by Coxhead (2000) consists of 570 word families that are not in the most frequent 2000 words of English ... but which occur reasonably frequently over a wide range of academic texts. These 570 words are grouped into ten sub-lists that reflect the frequency and range" (Coxhead 2000: 213; Kinsella 2003: 1) "For frequency, AWL word families had to occur over 100 times in the 3500000-word Academic Corpus. For range, the word families had to occur across disciplines (Coxhead 2000: 221; Victoria University 2007: 1). Because the 'Academic Word List' is not restricted to a specific field of study ... the words are useful for [students] studying in disciplines as varied as literature, science, health, business, and law" (Kinsella 2003:1).

The tasks here are aimed at actively involving students in categorising words, as in the parts of speech; forming 
words using prefixes and suffixes; defining words based on their own understanding, and dictionary definitions; making associations between words, on the basis of their meanings; and creating word games, for example Balderdash. With a large lexicon a student is positioned to access information from academic texts and read it with academic understanding.

\subsection{Reading for academic understanding}

The tasks included in this section of the course focus on reading, vocabulary building, post-reading comprehension exercises, investigating and using reading strategies, and academic writing. Such tasks are appropriate since "students [are expected] read thoughtfully and critically and produce evidence that makes and supports interpretations, make connections ... and evaluate writing strategies and elements of writing" (Intersegmental Committee of the Academic Senates of the California Communitiy Colleges, the California State University, and the University of California, ICAS, 2002:16). These higher-order reading skills facilitate academic rigour, are, in part, evidence of academic literacy. "Reading ability... is a critically important factor in academic success" (Van Rensburg and Weideman 2002: 158) ; because of the large volumes of reading that university students have to do, it is important that they know how to read efficiently, employing the correct reading strategies to maximise finding information relevant to the course(s), or sections thereof, being studied. Furthermore, competence in reading plays a key role in students' ability to write well. This is because good readers are able to find the appropriate information to complete a writing task. They are also able to read with understanding and communicate that understanding thoroughly to their lecturers. In addition, competent readers evaluate their writing against that of other academic writers, that is, they use the latter as a benchmark for their own writing (Weideman 2007: 111).

\subsection{Writing in an academic context}

The tasks included here involve scanning for information, using reference technique, mind mapping in preparation for a writing task, summarising information, searching for information, writing an introduction to an academic essay, constructing definitions, reflecting on written work, conducting and transcribing an interview, arranging interview data, keeping a reading record, and conducting a book review. This eclectic mix of tasks emphasises the fact that writing is a skill which is relies on one's integration of competences in speaking and listening, reading, vocabulary knowledge and gathering information.

Writing plays a key role in students' assessment at university. It is mainly through various written assignments such as academic essays and laboratory and field research reports, as well as responses to case studies, inter alia, that students demonstrate the insight that they have gained during their studies. In demonstrating this insight they are expected to communicate their ideas in accordance with the textual conventions of formality, conciseness and exactness, impersonality and objectivity, nominalisation, grammatical correctness, coherent and logical structure and argument, and appropriate use of evidence (Butler 2006). Adhering to such conventions would facilitate the acceptability (i.e. appropriateness, relevance and informativity) of these texts to the general academic writing conventions and the specific writing conventions stipulated by the courses they are doing. In so doing students will be meeting lecturers' expectations of them to imitate the forms and strategies of writing that they encounter in the text they read. In addition "[students] are ... expected to recognise that writing is a form of thinking and that sustaining arguments and synthesising ideas is the mainstay of their university writing experience" (ICAS 2002:15).

Writing involves bottom-up and top-down processing. Bottom-up processing depends on "knowledge of ... how to form words from letters, knowledge of the specific language in which the writing is taking place (including vocabulary and sentence structure), as well as the knowledge of the information that must be communicated in writing. Top-down processing includes knowledge of how to use information for a specific purpose and the ability to manipulate the information to an appropriate format, therefore using vocabulary choice, sentence, paragraph and discourse structure to achieve the desired goal" (Mitchell 2000:84). Students' ability to write well, employing bottom-up and top-down strategies, depends to a large extent on their prior knowledge and experience with writing. Thus prior knowledge in the form of linguistic and formal schemata is a necessary starting point for well written student texts in university (Mitchell 2000:61; Wessels, Van den Berg 1998: 203). In order to achieve this end product, they may follow the cyclical writing process.

This process is conventionally considered to have eight stages. It begins with thinking about the purpose of the writing, the potential audience and the appropriate register to use. This is followed by the information gathering stage which involves analysis and clarification of topic, establishing the purpose of writing, brainstorming, gathering information, discussion, and finding ideas to support evidence. Subsequent to the information gathering stage is the synthesis and structure stage involving preliminary synthesis of information that has been gathered and the arrangement thereof using 
the appropriate format. After this stage there is the drafting stage which involves free writing in full sentences. The drafting overlaps with the subsequent revision stage, as ideally it involves re-drafting which may be deemed necessary as one checks the written product against the assessment guide and goes back to the beginning if necessary. In the revision stage a writer reworks the draft, develops content, and focuses on arrangement of paragraphs in terms of clear main topic sentences and supporting sentences. In the subsequent editing stage the focus is on improvement of the written text in terms of grammar, vocabulary and punctuation. Where applicable, attention is also paid to imagery, tone and style. The submission stage is where the final version of the written text is submitted for assessment. Following submission and subsequent marking of the text is the remedial stage. This generally involves checking submitted and marked work in order to get an idea of its strengths and weakness. These are generally indicated in terms of a numerical figure given by the lecturer, and in some cases comments that accompany the mark in order to give clarity on the mark and guidance for improving future writing (Butler 2006: 61; Department of Education 2008:16; Lipkewich, Mazurenko 2001:1).

Clearly, writing is a complex and recursive process "in which the written text is reworked any number of times by an author towards a closer approximation of typically academic appropriateness and acceptability" (Butler 2006: 61). The cognitive and metacognitive skills needed to produce appropriate and acceptable academic writing include the ability to write clear and logical inductive and deductive arguments relating to the main point(s), to arrange and present facts and events logically, to create cohesion within a text, to use the reference techniques correctly within and at the end of a text, to use academic and technical vocabulary appropriately and to use vocabulary in general, in context (du Toit et al., 1995: 207-210; Coxhead 2000: 1; Mitchell 2000: 84-85; Ruby 1972: 59-71). The cognitive processing involved in academically literate behaviour is discussed in the next section which examines information processing as a fundamental process in academically literate behaviour.

\subsection{Processing information}

Information processing seems to be an important facet of being academically literate. While information processing is not included as a section in the academic literacy course used in the study, it is by all means an implied part of being academically literate; it underlies all aspects of academic literacy as it is crucial for effective listening, speaking, reading, writing, building of an academic vocabulary, information gathering, and learning at university. Strohm-Kitchener (1983:225-227) suggests that there are three levels of cognitive processing necessary for academic literacy. The first level (cognition) includes such tasks as calculating, memorising, reading and acquiring language. This level of cognitive processing is based on immediate, personal experience. The second level (metacognition) implies the ability (or inability) to think about and to evaluate one's own thinking. Metacognition refers to thinking about one's cognitive operations involved in learning, remembering and higher-level problem solving necessary for success in university studies (Mitchell 2000:34). It is an executive cognitive function that involves awareness of one's thought processes and the role that they play in the appropriateness of one's actions to the context in which one is operating.

Metacognition has the potential to play an important role in students monitoring their thought processes as they approach academic tasks. It can play a role in enhancing abilities demonstrative of academic literacy. If students pay attention to how they process information and directives in questions and requirements in academic reading, writing and assessment tasks, and make a conscious effort to adjust and/or adapt their thinking appropriately, this can facilitate optimal achievement in information production in tertiary education. The third level of cognitive processing includes the student's knowledge about limits of knowledge. According to Mitchell (2000:41) "it is this type of cognitive processing that it progressively demanded from university students. It indicates that the student has gained the ability to investigate whether problems can be solved, and which strategies will be required to do so". In other words it is crucial for students to understand how subject knowledge is created and challenged, in order to facilitate accessing and academic texts and tasks (Ratangee 2007:23).

\section{Academic Literacy and Cognition}

Academic literacy development programmes at South African universities generally take the form of an additional credit or non-credit-bearing module, participation in which in most cases is determined by prior assessment of students' need for academic literacy development. Based on Van Dyk and Weideman's (2004a:16) view of academic literacy, the focus of an academic literacy programme should be on enriching students' understanding of discourse practices within academia. Therefore, students' ability to engage critically with academic discourse in reading, writing, speaking, listening, and conducting research should inform the design of any academic literacy programme which seeks to be useful to them in their academic responsibilities and tasks. It is important that learning activities carefully guided by a facilitator are an 
integral part of the implementation of academic literacy development programmes. With such an approach "learners can move with guidance through the zone of proximal development and hone and develop their skills in an incremental way" (Mitchell, 2000:102). In addition to guidance through linguistically and cognitively challenging tasks mirroring academic literacy demands, students also need guidance through the technical language that many of them may find difficult in the initial years at university and perhaps even in the senior years.

Craig and Kernoff (1995: 23) suggest that academic literacy in the context of university learning is "the individual's ability to construct and reconstruct text, as well as compose and interpret meaning from written language and to written language". This compact conceptualisation of academic literacy captures the fact that students at university need to demonstrate their proficiency in academic discourse in information seeking, processing and producing activities in order to participate meaningfully and successfully in academic activities. In other words, "students at university are expected to independently, seek information, process that information and produce (new) information ... in authentic and realistic ways to demonstrate academic literacy (Weideman 2003b: 41).

A common mistake that is made by those in charge of academic literacy development initiatives at university is to regard reading and writing competence as the core of academic literacy, as was evident in the narrow perspectives discussed above in Craig and Kernoff (1995). This "skills perspective on language ... has the tendency to mislead one to believe that language can be perceived as a set of discrete skills" (Butler, 2006: 18). Furthermore, "language skills are not part of language ability at all, rather they are the contextualised realisation of the ability to use language in the performance of specific language use tasks. Therefore it is not useful to think of reading and writing skills as the foundation of academic literacy, but to think of academic literacy in terms of specific activities or tasks in which language is used purposefully" (Bachman and Palmer 1996: 75). Due to the "inseparable connection between language and ... context ... skill separation is ... a remnant of a bygone era besides, it has very little empirical or experiential justification" (Kumaravadivelu 2003:25).

Academic literacy involves communicating appropriately an academic context. This is achieved through the effective interaction of functional language ability together with information seeking, processing and production strategies in the context of a particular academic discourse (Bachman and Palmer, 1990: 87; Butler, 2006: 19; ICAS, 2002:16; Strohm-Kitchener 1983:225-227; Weideman 2003a: 2). The fact that academic literacy involves the use of complex cognitive skills is implied in the nature of academic tasks referred to in definitions of academic literacy in Ratangee (2007:24-25) and van Dyk and Weideman (2004a:16-17). The literature referred to in this article suggests that being academically literate involves being able to perform certain tasks rooted in and/or involving cognition which, in a nutshell, includes "encoding, storing, decoding, changing, and manipulating information that is gained through the senses. It also involves perception, awareness, judgement and understanding ... as well as problem solving" (Mitchell 2000: 34). Other cognitive tasks involved in academic literacy include, amongst others, interpreting information, understanding academic texts, reading critically, identifying relations between parts of a text, generating hypotheses, seeing sequence and order and making distinctions between fact and opinion, inferencing and extrapolating (Weideman 2007: xi-xii).

The cognitive aspect of academic literacy can also be summarised as critical thinking. Therefore, in the process of seeking, processing and producing information, academically literate university students "recursively engage in probative questioning, rigorous analysing, imaginative synthesising and evaluating of ideas" (ICAS 2002:14). The analysis and evaluation of ideas are the foundations of critical thinking, which is the type of thinking on which a premium is placed in academia (Butler, 2006: 29; Weideman 2007: xi-xii). In the processing of information, analysis can be further broken down into distinguishing, categorising and comparing an idea or argument before one can make a decision about its merit or its relevance to the context of study (Butler 2006:29-30).

\section{Conclusion}

By viewing academic literacy as having to do with 'epistemological access to higher education', academic literacy is seen to be related to specific cultural contexts and associated with the power and ideological relationships at play within those contexts (within, between and across settings, i.e., learning ecologies). It may therefore, be conclude that academic literacy constitutes a critical cognitive catalyst towards the creation of sustainable learning ecologies in higher education.

\section{References}

Angelil-Carter S 2000. Access to success: academic literacy in higher education. Cape Town: University of Cape Town Press.

Bailey KM, Nunan D 1996. Voices from the language classroom: Qualitative research in second language education. Cambridge: Cambridge University Press. 
Baynham M 1995. Literacy practices: Investigating literacy in social contexts. London: Longman.

Barnes R 1996. Successful study for degrees. London: Routledge.

Barron B 2006. Interest and self-sustained learning as catalyst of development: A learning ecology perspective. Human Development, 49:193224.

Biggs J, Tang C 2009. Teaching for quality learning at university. 3rd edition. Berkshire, England: McGraw Hill.

Boughey C 2000. Multiple metaphors in an understanding of academic literacy. Teachers and teaching: Theory to practice 6 (3):279-290.

Boughey C 2002. 'Naming' students' problems: An analysis of language-related discourses at a South African university. Teaching in Higher Education 7 (3): 295-307.

Braine G 2002. Academic literacy and the non-native speaker graduate student. Journal of English for academic purposes 1: 59-68.

Cannell P, Hewitt LND, Butler GH 2006. A framework for course design in academic writing for tertiary education. Unpublished doctoral thesis. University of Pretoria.2010. Access to higher education, language and academic literacy. [Online]. Available http://www.wikieducator.org limages/0/04/PID 213.pdf. Accessed 6 January 2010.

Cartsens A 2008. A multidirectional model for tertiary-level disciplinary writing. Journal for Language Teaching 42 (1): 1-17.

Conference on language assessment and the national qualifications framework 1996. Language assessment and the national qualifications framework: conference proceedings, 12 October 1995. Pretoria: Human Sciences Research Council.

Cooper P, Van Dyk T 2003. Measuring vocabulary: A look at different methods of vocabulary testing. Perspectives in Education 21 (1): 67-80.

Coxhead A 2000. A new academic wordlist. TESOL quarterly 34 (2):213-238.

Craig AP, Kernhoff RJ 1995. Development of textual interpretation by underprepared students. South African Journal of Higher Education 9 (1): 23-30.

De Vos AS, Stydom H, Fouche CB, Delport CSL 2005. Research at grass roots: for the social sciences and human service professions. Pretoria : Van Schaik publishers.

Daems F, Leysen J, Messerschmidt H, Rymenans R 1999. Theoretical models of language acquisition. In Elen, J. 1999. 27-39.

Delport CSL 2005.Quantitative data collection methods. In De Vos, A.S., Strydom, H., Fouche C.B. and Delport, C.S.L. 2005:165-196.

Department of Education 2001. National plan for higher education in South Africa. [Online]. Available http://education.pwv.gov.za/Doe_sites /Higher. Accessed 23 April 2010.

Department of Education 2002a. Revised National Curriculum Statement Grades R-9 (Schools): Teachers' guide for the development of Learning Programmes: Languages. Pretoria: Department of Education.

Department of Education 2003. National Curriculum Statement Grades 10-12 (General): Languages. Pretoria: Department of Education.

Du Toit P, Heese M, Orr M 1995. Practical guide to reading, thinking and writing skills. Halfway House: Southern Book Publishers

Durrheim K 2002. Quantitative measurement. In M. Terre Blanche, and Durrheim, K. 2002. (eds.). 2002:72-96.

Elen J 1999. Learning history: Language, instructional and assessment issues. Literature review of the PHAPHAMANG-PROJECT. University of Leuven: Centre for Instructional Psychology and Technology.

Fairclough N 1992a. Discourse and social change. Cambridge: Polity Press.

Fairclough N 1992b. Critical language awareness. London: Longman.

Frere P 2006. Pedagogy of the oppressed. New York: Continuum.

Fulcher G, Davidson F 2007. Language testing and assessment: An advanced resource book. London: Routledge.

Department of Education 2002a. Revised National Curriculum Statement Grades R-9 (Schools): Teachers' guide for the development of Learning Programmes: Languages. Pretoria: Department of Education.

Gauteng Department of Education 2008. Portfolio guideline document for languages: Home language, First additional language, Second additional language. Pretoria: Department of Education.

Gee JP 2003. Opportunity to learn: A language-based perspective on assessment. Assessment in Education 10 (1): 27-46.

Haggett P 2001. Geography: A global synthesis. Harlow, England: Prentice-Hall.

Harrison A 1986. A language testing handbook. London: Macmillan.

Hartshorne KB 1987. Language policy in African education in South Africa 1910-1985 with particular reference to the medium of instruction. In Young, D. (ed.). 1987. Language: Planning and medium in education. Cape Town: The Language Education Unit and SAALA: 82-106.

Hornberger NH 2008. (ed). Encyclopaedia of language and education. New York: Springer.

Hornby AS 2000. Oxford Advanced Learners' Dictionary of Current English. Oxford: Oxford University Press.

Hughes A 2003. Testing for languages teachers. Cambridge: Cambridge University Press.

Intersegmental Committee of the Academic Senates of the California Communitiy Colleges, the California State University, and the University of California (ICAS), 2002. Academic literacy: A statement of competencies expected of students entering California's public colleges and universities. [Online]. Available http://www.calstate.edu/AcadeSen/Records/ ... IAcademic_literacy_Fianl.pdf.Accessed 14 September 2010.

Kamwangamalu NM 2008. Second and foreign language learning in South Africa. In Van Deusen-Scholl, N. \& Hornberger, N.H. (eds). 2008: 183195. Encyclopaedia of language and education. $2^{\text {nd }}$ edition. Volume 4: Second and foreign language education.

Kaplan RB (ed). 2000. The Oxford handbook of applied linguistics. Oxford: Oxford University Press.

Kelly K 2002. Data-gathering in interpretive research. In Terre Blanche, M. \& Durrheim, K. (eds.). 2002. 379-397. Research in practice: Applied methods for the social sciences. $2^{\text {nd }}$ edition. Cape Town: University of Cape Town Press.

Kilfoil WR, Van der Walt C 1997. Learn 2 teach. English language teaching in a multilingual context. Pretoria: Van Schaik

Kinsella 2003. The Academic Word List (Averil Coxhead, 2000): a list of 570 high-incidence and high-utility academic word families for Secondary School, Higher Education, Career. [Online]. Available

http://teacher.scholastic.com/products/read180/community/pdfs/Vocabulary/Academic_Word_List_by_Frequency.pdf. Accessed 23 August 2011.

Krashen SD 1988. Second language acquisition and second language learning. Hemel Hempstead: Prentice Hall International (UK) Ltd.

Kumaravadivelu S 2003. Beyond methods: Macrostrategies for language teaching. London: Yale University Press.

Lapman C, Corson D 1997. Language testing and assessment. Boston: Kluwer Academic.

Lipkewich AE, Mazurenko R 2001. ABCs of the writing process. [Online]. Available http//www.angelfire.com/wi/writing process. Accessed 16 
November 2010.

Littlewood WL 1984. Foreign and second language learning: Language acquisition research and its implications for the classroom. Cambridge: Cambridge University Press.

McKenna S 2008. What is academic literacy when it's in my classroom? [Online]. Available http://www.academic.sun.a.c.za/fyeconference2008 /Documentation/Workshop. Accessed 19 October 2009.

McKenna S 2010. Cracking the code of academic literacy: An ideological task. In: C Hutchings \& J Garraway. Beyond the university gates: Provision of Extended Curriculum Programmes in South Africa.

McWhorter KT 1992. Study and thinking skills in college. 2nd edition. New York: Harper Collins Publishers.

Miller R 1997. Mark my words, part 2: students. South African Journal of Higher Education 11(1): 11-18.

Ministry of Education 1997. Language-in-education policy.

[Online]. Available http://www.education.gov.za/Documents/policies/Language EducationPolicy1997.pdf. Accessed 10 September 2007.

Ministry of Education 2002. Language policy for Higher Education. [Online]. Available http://www.education.gov.za/content/documents/67.pdf. Accessed 13 November 2009.

Mitchell JE 2000. Strategies for the development of academic literacy of first-year education students at Vista University. Unpublished doctoral thesis. Pretoria: UNISA.

Moore R 1998. How Science educators construe student writing. In S. Angelil-Carter. 1998. (ed.). 1998: 83-101.

Olivier J 2006. South Africa: Language \& Education. [Online]. Available http://www.cyberserv.co.za/users/jako/language/education.htm. Accessed 20 September 2008.

Paxton M 1998. Transforming assessment practices into learning processes. In S. Angelil-Carter. 1998. (ed.). 1998:136-153.

Paxton M 2007. Students' interim literacies as a dynamic resource for teaching and transformation. Southern African linguistics and applied language studies 25 (1): 45-55.

Pugh SL, Pawan F, Antonmmarchi A 2000. Academic literacy and the new college learner. In Flippo, F. and Caverley, D.C. (eds.). $2000: 25-42$. Handbook of college reading and study strategy research. Mahwah: Lawrence Erlbaum Associates.

Ratangee N 2007. Chapter three: Academic literacy. [Online]. Available http://www.witsetd.wits.ac.za:8080/dspace/bitstream/.../Ratangee_ Chapter3.pdf. Accessed 19 October 2009.

Reid J 2005a. Academic literacy. [Online]. Available http://www.une.edu.au/tlc/alobefore1.htm. Accessed 19 October 2009.

Reid J 2005b. What is academic literacy? [Online]. Available http://www.before2.htm. Accessed 19 October 2009.

Ruby L 1972. The art of making sense. Tokyo: Yohan Publications Inc.

Spack R 1997. The acquisition of academic literacy in a second language: A longitudinal study. Written Communication 14 (1): 3-62.

Strohm-Kitchener K 1983. Cognition, metacognition, and epistemic cognition: a three-level model of cognitive processing. Human Development 26:222-232.

Terre Blanche M, Durrheim K 2002. Social constructionist methods. In M. Terre Blanche, and Durrheim, K. 2002. (eds.). 2002: 147-172. Research in practice: Applied methods for the social sciences. $2^{\text {nd }}$ edition. Cape Town: University of Cape Town Press.

Terre Blanche M, Durrheim K (eds). 2002. Research in practice: Applied methods for the social sciences. $2^{\text {nd }}$ edition. Cape Town: University of Cape Town Press.

Turner J 2004. Academic literacy in post-colonial times: Hegemonic norms and transcultural possibilities. In Phipps, A.M. and Guilherme, M. (eds.). 2004: 22-32. Critical pedagogy: Political approaches to language and intercultural communication. Clevendon, United Kingdom: Multilingual Matters.

Underwood G, Batt V 1996. Reading and understanding. Oxford: Blackwell Publishers.

von Meyer H 1997. Rural employment in OECD Countries: Structure and dynamics of regional labour markets. In Bollman RD and Bryden JM (eds.). 1997: 22-35. Rural Employment. Brandon, Canada: Canadian Rural Restructuring Foundation.

Van Dyk T, Weideman A 2004a. Switching constructs: On the selection of an appropriate blueprint for an academic literacy assessment. SAALT Journal for Language Teaching 38 (1): 1-13.

Van Dyk T, Weideman A 2004b. Finding the right measure: From blueprint to specification to item type. SAALT Journal for Language Teaching 38 (1): $15-24$

Van Schalkwyk SC 2008. Acquiring academic literacy: A case of first-year extended degree programme students at Stellenbosch University. PhD thesis.

Victoria University 2007. AWL Selection.[Online]. Available

http://www.victoria.ac.nz/lals/resources/academicwordlist/principles/aspx. Accessed 23 August 2011.

Weideman A J 2002. Designing language teaching: On becoming a reflective professional. Pretoria: Van Schaik.

Weideman AJ 2003a. Academic literacy: Prepare to learn. Pretoria: Van Schaik.

Weideman AJ 2003b. Justifying course and task design in language teaching. Acta Academia 35(3):26-48.

Weideman AJ 2007. Academic literacy: Prepare to learn. Pretoria: Van Schaik.

Wessels M, Van den Berg R 1998. Practical guide to facilitating language learning. Halfway House: International Thomson Publishing. 